Published in final edited form as:

Neuroimage. 2019 January 15; 185: 446-454. doi:10.1016/j.neuroimage.2018.10.051.

\title{
Neural correlates of effort-based valuation with prospective choices
}

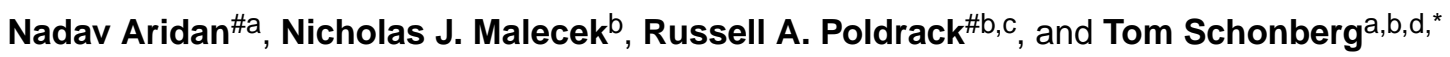 \\ aDepartment of Neurobiology, Faculty of Life Sciences, Tel Aviv University, Tel Aviv, 6997801, \\ Israel \\ bImaging Research Center, The University of Texas at Austin, 100 E $24^{\text {th }}$ St, Stop R9975, Austin, \\ TX, 78712, USA \\ 'Department of Psychology, Stanford University, Bldg. 420, Jordan Hall, Stanford, CA, 94305, \\ USA \\ dSagol School of Neuroscience, Tel Aviv University, Tel Aviv, 6997801, Israel \\ \# These authors contributed equally to this work.
}

\begin{abstract}
How is effort integrated in value-based decision-making? Animal models and human neuroimaging studies primarily linked the anterior cingulate cortex (ACC) and ventral striatum (VS) to the integration of effort in valuation. Other studies demonstrated the role of these regions in invigoration to effort demands, thus it is hard to separate the neural activity linked to anticipation and subjective valuation from actual performance. Here, we studied the neural basis of effort valuation separated from performance. We scanned forty participants with fMRI, while they were asked to accept or reject monetary gambles that could be resolved with future performance of a familiar grip force effort challenge or a fixed risk prospect. Participants' willingness to accept prospective gambles reflected discounting of values by physical effort and risk. Choice-locked neural activation in contralateral primary sensory cortex and ventromedial prefrontal cortex (vmPFC) tracked the magnitude of prospective effort the participants faced, independent of choice time and monetary stakes. Estimates of subjective value discounted by effort were found to be tracked by the activation of a network of regions common to valuation under risk and delay, including vmPFC, VS and sensorimotor cortex. Together, our findings show separate neural mechanisms underlying prospective effort and actual effort performance.
\end{abstract}

\section{Keywords}

Physical Effort; Risk, Prospection; Mixed-gambles; fMRI; Decision-making

*Correspondence: Tom Schonberg, Department of Neurobiology, Faculty of Life Sciences and Sagol School of Neuroscience, Tel Aviv University, Tel Aviv, 6997801, Israel. schonberg@ post.tau.ac.il.

Publisher's Disclaimer: This is a PDF file of an unedited manuscript that has been accepted for publication. As a service to our customers we are providing this early version of the manuscript. The manuscript will undergo copyediting, typesetting, and review of the resulting proof before it is published in its final citable form. Please note that during the production process errors may be discovered which could affect the content, and all legal disclaimers that apply to the journal pertain. 


\section{Introduction}

Maladaptive sensitivity to effort is known to play a key role in multiple disorders that feature symptoms of impaired motivation such as apathy, major depression and schizophrenia (Chong and Husain, 2016; Cléry-Melin et al., 2011; Gold et al., 2013; Salamone et al., 2006). Furthermore, overweighting of effort costs was found to be linked with physical inactivity and sedentary lifestyle (Bernacer et al., 2016), a major risk factor for diseases and millions of premature deaths worldwide each year (Lee et al., 2012). Understanding how humans evaluate energetic costs to form decisions and the underlying neural processes offers great potential for developing treatments and interventions for impaired motivation. However, despite considerable advances (for review see: Wallis and Rushworth, 2013), the mechanisms of effort-based decision-making remain unclear.

Effortful behavior, whether among laboratory participants or foraging animals, generally demonstrates that effort imposes a cost on valuation, revealed by preferences for less effortful alternatives (Charnov, 1976; Hull, 1943; Rudebeck et al., 2006). Theoretical models of valuation suggest that the integration of expected cost and benefit representations guide economic choice behaviors (Padoa-Schioppa, 2011; Rangel et al., 2008). Within these models, effort is integrated with other motivational determinants as a cost in the computation of subjective value. Multiple studies have demonstrated the devaluation of rewards by effort cost (for review see: Chong et al., 2016). Converging evidence from animal models and human neuroimaging studies link integrated value to neural activity within a network of regions that include the ventral striatum (VS), posterior cingulate cortex, anterior insula and ventromedial prefrontal cortex (vmPFC; Bartra et al., 2013; Clithero and Rangel, 2013; Rushworth and Behrens, 2008) and demonstrate modulation of its activity by common costs such as risk (Mohr et al., 2010) and delay (Carter et al., 2010). However, accounts of effortbased valuation have instead emphasized the specific role of the anterior cingulate cortex (ACC) together with VS. For example, animals with lesions to ACC (Rudebeck et al., 2006; Walton et al., 2003), or depletion of dopamine within VS (Salamone et al., 2007) fail to allocate effort properly to maximize available rewards. Patterns of phasic dopamine release within VS (Day et al., 2010) and the activity of single neurons within ACC reflect the association of effort cost to expected reward in isolation (Pasquereau and Turner, 2013) and competitive contexts (Hillman and Bilkey, 2012). Human neuroimaging studies extended the relationship of VS to effort-discounted reward (Croxson et al., 2009; Kurniawan et al., 2010) and the ACC to effort-based cost-benefit analyses (Kurniawan et al., 2013; Prévost et al., 2010). Related studies also implicated primary and supplementary motor areas (SMA), insula and posterior parietal cortex as sensitive to expected effort costs (Burke et al., 2013; Croxson et al., 2009; Meyniel et al., 2013; Skvortsova et al., 2014). Together, effort-based valuation studies have consistently emphasized the relationship of ACC and VS to effortful behavior, but inconsistently present several possible loci for the integration of effort and value.

Effort relates to the difficulty of performing a behavior, such as physical force or response rate required within a limited time. Previous reports typically presented effort costs within passive or forced choice paradigms that demanded invigoration to meet upcoming effort challenges (Croxson et al., 2009; Kurniawan et al., 2013; Prévost et al., 2010). This is a 
distinct process from the prospective imposed cost of effort upon the subjective value of a potential outcome. Accordingly, recent reports suggest that ACC and VS activations in effort-based tasks may reflect these invigoration demands, rather than the valuation processes (Holec et al., 2014; McGinty et al., 2013; Shenhav et al., 2014). Similarly, single neurons within ACC were shown to exhibit encoding of task demands more often than effort-discounted value (Hosokawa et al., 2013). To specifically target effort- and risk-cost valuation, we developed a paradigm that presented participants with choices about effort and risk separated from effort production and outcome resolution. Participants were first trained to associate cues with physical grip force effort levels. In a subsequent choice phase, participants rated the subjective attractiveness of mixed gambles that offered a monetary gain or loss from their initial endowment. The outcome of these mixed gambles could depend upon future effort performance. Participants separately made similar choices in a task with fixed risk prospects. We hypothesized that prospective effort would impose a cost upon decision makers, reflected in both their willingness to gamble and neural activation related to value. Neuroimaging analyses examined the relationship of neural activity during choice to the magnitude of potential gain, loss and effort or risk present in each gamble. We further separately tested neural correlates of behavioral model-based predictions of subjective value from each task. Thus, we present a novel approach to characterize the neural basis of valuation under prospective effort, a common cost in economic choices. We share all neuroimaging and behavioral data as well as analyses codes used.

\section{Materials and Methods}

\subsection{Participants}

Forty-six healthy, right-handed participants recruited from the University of Texas at Austin community participated in the experiment. Six participants were excluded from further analyses due to either excessive head movement, MRI artifacts or failure to meet behavioral criteria described below. The remaining forty participants comprised the sample group for our fMRI analyses (mean age $=22.62$ years, standard deviation $=2.90$ years, 21 females). Sample size was determined a priori by a power analysis for a contrast of interest (parametric prospective effort) from a pilot study of 13 participants (mean age $=21.3$ years, standard deviation 2.31 years, 7 females) with the fMRIpower software package (Mumford and Nichols, 2008). Each participant provided informed consent prior to the experiment. All participants had normal or corrected-to-normal vision, reported no history of psychiatric diagnoses, and neurologic or metabolic illnesses. The Institutional Review Board at the University of Texas at Austin approved all experimental procedures.

\subsection{Behavioral paradigm}

2.2.1. General methods-Prior to the experiment, participants were endowed with $\$ 20$ cash. Participants were instructed that they were participating in a study about preferences in economic choices. Stimuli presentation and participant response collection were implemented with custom MATLAB code and the Psychophysics toolbox (Brainard, 1997).

2.2.2. Baseline force measurement-Once inside the MRI scanner, each participant's maximum voluntary contraction (MVC) force was assessed with an MR- 
compatible dynamometer (BIOPAC TSD121B-MRI, BIOPAC Systems Inc., USA). Participants were prompted to squeeze the dynamometer with their right hand as hard as possible in three intervals of two seconds interspersed with periods of rest for two seconds (Fig. 1A). The calibration procedure was performed without feedback or incentives. The average force assessed by this procedure was considered the participants' MVC for calibration of the training and test task phases. After calibration, participants were shown a display with real-time force feedback for demonstration purposes.

2.2.3. Effort training - To examine the role of effort in economic choices, participants were first trained to associate color and height cues with the performance of physical grip effort levels. For each participant, five effort levels were determined at 30, 40, 50, 60 and $70 \%$ of their calibrated MVC (Fig. 1B). During the effort training phase, participants attempted to complete physical grip effort production trials without incentives at five levels of difficulty. Each training run consisted of 80 total trials, 16 trials at each effort level, drawn randomly from one of five orders optimized for event-related fMRI. To successfully complete a trial, participants were required to exert grip force at or above a given effort level for at least 1 second of total time within a 2 second response period. Participants received two types of feedback during the training phase: real-time effort production level (dynamically adjusted height of red bar in effort display, Fig. 1C) and success or failure to meet the effort goal on a trial-by-trial basis.

2.2.4. Prospective effort mixed gambles-Following the effort training session, participants rated the attractiveness of prospective effort mixed gambles. Each mixed gamble presented participants with three components: a potential gain in addition to their endowment (\$2-\$12 in \$2 increments); a potential loss from their endowment (\$1-\$6 in \$1 increments) and one of the five effort levels established in the previous training session (30, 40, 50, 60 and 70\% of calibrated MVC force; Fig. 1D). There were 180 trials in the choice set, all 36 combinations of potential gain and loss at each of the five effort levels. Effort level trial order and inter-stimulus interval timing were determined by an efficiency calculation for the prospective effort contrast of interest (Kao et al., 2009). Potential gain and loss amounts were drawn from the choice set for each effort level randomly without replacement. To encourage participants to reflect on the subjective attractiveness of mixed prospects rather than a fixed decision rule (e.g. accept all gambles with potential gain > \$6), we asked participants to indicate one of four responses to each gamble (strongly accept, weakly accept, weakly reject, and strongly reject) as quickly as possible with a four-button response box. Participants were instructed that one gamble trial would be drawn at random at the end of the experiment. If the gamble was accepted, the resolution of the gamble (monetary gain or loss) would depend upon successful performance of the indicated effort level five times in succession without error at the end of the experiment as practiced during the earlier training session. If the randomly selected gamble trial was previously rejected, then no gain or loss would occur to their endowment.

2.2.5. Prospective risk mixed gambles-To compare effort-based valuation with valuation under risk, participants completed a similar set of prospective risk mixed gambles. This phase always followed the effort mixed gambles phase to limit potential framing effects 
(e.g. thinking of prospective efforts in terms of fixed probabilities). Prospective risk gambles also presented participants with three components: a potential gain in addition to their endowment (\$2-\$12 in \$2 increments), and a potential loss from their endowment (\$1-\$6 in $\$ 1$ increments), and one of five winning probability levels (10, 30, 50, 70 and 90\%; Fig. 1E). The five levels were selected to span a wide range of success probabilities. Trial orders and choice sets were constructed similarly to the previous phase for the prospective risk contrast of interest. Participants indicated one of four responses as above to each trial and were informed that one trial from this phase would be selected at random at the end of the experiment and its outcome honored according to their choice to accept or reject, as in the previous phase.

2.2.6. Confidence ratings-To assess the effect of the grip force effort training paradigm on subsequent prospective effort gamble valuations, participants were asked to rate how confident they were that they could perform five successive grip force trials, as in the training phase, at nine levels (10-90\% of their MVC in 10\% increments). Participants used a button pad to freely indicate between 0 and $100 \%$ confidence in their ability to successfully perform a grip force at each effort level. This phase was always completed after both effort and risk mixed gamble phases to limit probability-based framing effects during prospective gambles valuations.

2.2.7. Resolution-Finally, while still in the scanner, participants faced the resolution of each prospective gamble phase. One trial from the prospective effort mixed gambles phase and one trial from the prospective risk mixed gambles phase, were randomly selected. For each selected trial, if the participant indicated 'strong reject' or 'weak reject' to the randomly drawn gamble, the associated gamble resolution phase ended without gain or loss. However, if for the selected trial the participant responded with 'strong accept' or 'weak accept', the drawn gamble was played out as follows: For the selected trial from the prospective effort mixed gambles phase, participants were required to attempt five consecutive physical grip force trials at the effort level of the randomly drawn prospect (e.g. $40 \%$ in Fig. 1C). For the selected trial from the prospective-risk mixed gambles phase, participants passively viewed the outcome of the randomly drawn gamble played out by the computer. For each case, success resulted in the monetary gain associated with the drawn gamble and failure resulted with the associated loss. All monetary gains or losses that incurred in the resolution phase were added or subtracted from the participant's initial endowment. After the experiment, participants were debriefed and paid in cash for their time and the results of the mixed gamble resolutions.

\subsection{Behavioral analyses}

We tested participants' overall willingness to gamble (proportion of gambles accepted) prior to other behavioral analyses. This test revealed two participants that failed to meet a predetermined behavioral threshold (accepted or rejected more than $95 \%$ of all gamble trials) and excluded them from further analyses. From the training phase, we calculated mean success rate (percentage of making the goal in effort trials). We fit a binary-logistic mixed-effects regression model to each of the mixed gambles phases to predict gamble acceptance with prospective effort or risk, gain and loss magnitudes as fixed effects and the 
participants as random effect. In addition, we fit a linear model to predict acceptance rates across the different gamble components and reaction times. Finally, mean confidence rates were calculated from the confidence rating phase. All statistical analyses were performed in $\mathrm{R}$ using lme4 package with a BOBYQA optimizer (Bates et al., 2015). In all cases the fitted model convergence was achieved prior to the maximal limit of 10,000 iterations. P-values were calculated using the lmerTest package (Kuznetsova et al., 2017).

\subsection{Neuroimaging}

2.4.1. Image acquisition-Imaging data were acquired on a 3 Tesla Skyra MRI scanner system (Siemens) with a 32channel head coil. Anatomical images for registration to Montreal Neurological Institute (MNI) template space were acquired with a high-resolution magnetization prepared rapid gradient echo (MPRAGE) pulse sequence (TR $=1900 \mathrm{~ms}$, TI $=900 \mathrm{~ms}, \mathrm{TE}=2.43 \mathrm{~ms}$, flip angle $=9^{\circ}, \mathrm{FOV}=256$, voxel size $1.0 \times 1.0 \times 1.0 \mathrm{~mm}$ ). Functional images were acquired with a $\mathrm{T} 2 *$ weighted multiband echo-planar imaging sequence $(\mathrm{TR}=1000 \mathrm{~ms}$, multiband acceleration factor $=4$, iPAT parallel acceleration factor $=2, \mathrm{TE}=30 \mathrm{~ms}$, flip angle $=63^{\circ}, \mathrm{FOV}=230$, voxel size $2.4 \times 2.4 \times 2.4 \mathrm{~mm}$; Moeller et al., 2010). For functional scans, fifty-six gapless axial slices were positioned $30^{\circ}$ off the anterior commissure-posterior commissure line to reduce frontal signal dropout (Deichmann et al., 2003). Higher-order shimming was used to reduce susceptibility artifacts.

2.4.2. fMRI data preprocessing-Raw DICOM data images were converted to NIFTI format and organized to conform to the 'Brain Imaging Data Structure' specifications (BIDS; Gorgolewski et al., 2016). Preprocessing was conducted using FMRIPREP (version 1.0.0-rc13; Esteban et al., 2018; K. Gorgolewski et al., 2011, 2017). Within the FMRIPREP framework, each $\mathrm{T} 1$ weighted volume was corrected for bias field using N4BiasFieldCorrection v2.1.0 (Tustison et al., 2010) and skullstripped using antsBrainExtraction.sh v2.1.0 (using OASIS template). Cortical surface was estimated using FreeSurfer v6.0.0 (Dale et al., 1999). The skullstripped T1w volume was coregistered to skullstripped ICBM 152 Nonlinear Asymmetrical template version 2009c (Fonov et al., 2009) using nonlinear transformation implemented in ANTs v2.1.0 (Avants et al., 2008). Functional data was motion corrected using MCFLIRT v5.0.9 (Jenkinson et al., 2002). This was followed by co-registration to the corresponding T1-weighted volume using boundary based registration 9 degrees of freedom - implemented in FreeSurfer v6.0.0 (Greve and Fischl, 2009). Motion correcting transformations, T1 weighted transformation and MNI template warp were applied in a single step using antsApplyTransformations v2.1.0 with Lanczos interpolation. Three tissue classes were extracted from T1w images using FSL FAST v5.0.9 (Zhang et al., 2001). Voxels from cerebrospinal fluid and white matter were used to create a mask in turn used to extract physiological noise regressors using a CompCor (Behzadi et al., 2007). Mask was eroded and limited to subcortical regions to limit overlap with gray matter, six principal components were estimated. Frame-wise displacement (Power et al., 2014) was calculated for each functional run using Nipype implementation. Spatial smoothing of functional images was performed with a Gaussian kernel with a fullwidth half maximum of $5 \mathrm{~mm}$. Data and design matrices were high-pass filtered with a Gaussian-weighted least-squares straight line fit with a cutoff period of 100 s. Grand-mean 
intensity normalization of each functional image volume's entire four-dimensional data set was performed by a single multiplicative factor.

2.4.3. fMRI data analyses-All neuroimaging analyses focused on neural activity at the time of prospective valuation. In each whole-brain analysis, general linear models assessed the relationship of neural activity to mixed gamble variables or subjective value model predictions. The first whole-brain parametric model (GLM1) modeled five parametric regressors, three from the prospective effort mixed gambles phase: monetary gain, monetary loss and physical-demand (grip force effort level). To account for the uncertainty component of the effort phase (probability of not making the goal), two additional regressors modeled actual success-probability (goal success rate during training), and perceived successprobability (post task confidence rating). A second whole-brain parametric model (GLM2) modeled three parametric regressors from the prospective risk mixed gambles phase: monetary gain, monetary loss and prospective risk level associated with gamble resolution. In both models, parametric mixed gamble regressors were chosen to identify brain regions wherein activation or deactivation correlated with magnitude of each regressor, independent of changes in the other regressors without orthogonalization (Mumford et al., 2015). A second set of analyses (GLM3) and (GLM4) modeled a parametric regressor that reflected an estimate of a participant's probability of accepting a gamble from the effort- and riskbased phases, respectively. For each participant, responses were collapsed into accept or reject categories and a binary logistic regression was fitted to predict response by the size of the potential gain, loss and effort (GLM3) or risk (GLM4). We then applied the resulting logistic equation parameters to generate a predicted probability of gamble acceptance regressor for each trial for each phase. In a separate whole brain-analyses, these regressors were used to identify brain regions that tracked the predicted probability of accepting a gamble, an estimate related to the subjective value of the gamble at choice. The binary logistic regression equations followed the forms:

$$
\begin{aligned}
& \operatorname{GLM} 3: \mathrm{p}_{(\text {accept })}=\frac{e^{\left(\beta_{0}+\beta_{\text {gain }} \cdot X_{\text {gain }}+\beta_{\text {loss }} \cdot X_{\text {loss }}+\beta_{\text {effort }} \cdot X_{\text {effort }}\right)}}{1+e^{\left(\beta_{0}+\beta_{\text {gain }} \cdot X_{\text {gain }}+\beta_{\text {loss }} \cdot X_{\text {loss }}+\beta_{\text {effort }} \cdot X_{\text {effort }}\right)}} \\
& \text { GLM4: } \mathrm{p}_{(\text {accept })}=\frac{e^{\left(\beta_{0}+\beta_{\text {gain }} \cdot X_{\text {gain }}+\beta_{\text {loss }} \cdot X_{\text {loss }}+\beta_{\text {risk }} \cdot X_{\text {risk }}\right)}}{1+e^{\left(\beta_{0}+\beta_{\text {gain }} \cdot X_{\text {gain }}+\beta_{\text {loss }} \cdot X_{\text {loss }}+\beta_{\text {risk }} \cdot X_{\text {risk }}\right)}}
\end{aligned}
$$

In all GLMs participants' reaction times were modeled using the mean centered trial-by-trial reaction time. Additional regressors of no interest included all trials unmodulated (intercept), trials without behavioral responses, and nine confound regressors derived from preprocessing with FMRIPREP. These nine regressors included six motion parameters over time (rigid-body $x-y-z$ translation and rotation transform ) and three derivative of RMS variance over voxels (standardized, non-standardized and voxel-wise standardized). All statistical analyses were corrected for multiple comparisons with Gaussian Field Theory (GFT). Whole-brain cluster-forming threshold was $\mathrm{z}=2.3$, $\mathrm{p}<0.01$ and FWE cluster size threshold of $\mathrm{p}<0.05$. In addition, we have produced overlapping maps for each comparison between the different contrasts of interest in the different GLMs (see supplementary, Figures 
1-4), performed a conjunction-null test for overlapping activity of prospective effort and risk (Nichols et al., 2005) and a paired t-test for difference between the two tasks.

\subsection{Data sharing}

Unthresholded whole-brain statistical maps of activations are available for reference at NeuroVault.org (Gorgolewski et al., 2015) (https://neurovault.org/collections/3955/.

Neuroimaging data necessary to recreate all analyses will be made available as part of the OpenNeuro project (Poldrack \& Gorgolewski, 2017) https://openneuro.org/datasets/ ds001167. Behavioral data, analysis codes and fMRI analysis codes as well are available at: osf.io/mb3qw.

\section{Results}

\subsection{Behavioral Results}

3.1.1. Behavior: effort training-Participants' behavior reflected modulation by effort, whereby success rates on effort training trials and post task confidence ratings decreased as the level of effort increased (Fig. 2A). In the training phase, increased effort requirements reduced the probability of successful performance $(\mathrm{OR}=0.92,95 \%$ CI $[0.91,0.93], \mathrm{p}<$ 0.001). Averaging training performance within each effort level for each participant showed a strong negative linear correlation of effort level and training success ratio: $\left(r=-0.81, \mathrm{t}_{(159)}\right.$ $=-10.12, \mathrm{p}<0.001$; see supplementary Table 2 for individual participants results).

Similarly, post-task confidence ratings of effort performance decreased as effort increased ( $\mathrm{r}$ $=-0.50, \mathrm{t}_{(319)}=-17.95, \mathrm{p}<0.001 ;$ Fig. $\left.2 \mathrm{~A}\right)$.

3.1.2. Behavior: mixed gambles-Participants' overall willingness to gamble reflected an effect of prospective effort and risk costs (see Table 1). In the mixed gambles effort task, as the level of prospective effort increased, probability of gamble acceptance decreased. Similarly, in the mixed gambles risk task, prospective risk reduced average gamble acceptance rates.

Participants' median reaction times followed a negative quadratic relationship (i.e. slowest median RT for gambles accepted on average $50 \%$ of the time) under prospective effort $\left(\mathrm{R}^{2}=\right.$ $0.60, \mathrm{p}<0.001)$ and prospective risk $\left(\mathrm{R}^{2}=0.78, \mathrm{p}<0.001\right.$; Fig. $\left.2 \mathrm{~B}\right)$. To illustrate participants' choice preferences for mixed gambles under prospective effort and risk, gain and loss levels were collapsed into 3 bins each . Group average acceptance rates for effortbased gambles (Fig. 2C) and risk-based gambles (Fig. 2D) illustrate a pattern of decreased willingness to gamble across the entire choice set as prospective effort or risk increased.

\subsection{Neuroimaging results}

3.2.1. Whole-brain parametric mixed gambles-Parametric analyses of neural activation at choice (GLM1, GLM2) revealed activity in distinct brain regions that was modulated by the components of effort- and risk-based mixed gambles tasks (Fig. 3). Increased activation for increasing prospective effort was found in left primary sensory cortex and increased activity for decreasing physical-demand was found in vmPFC (Fig. $3 \mathrm{~A})$. In contrast, increased activation for increased prospective risk showed a broader region 
that included left sensorimotor cortex and left superior parietal lobule. Decreased activation for increased prospective risk was found within the medial frontal cortex, anterior and posterior cingulate cortex, right striatum, frontal polar cortex and right sensorimotor cortex (Fig. 3D). In both the effort and risk tasks increasing prospective gain corresponded with increased activity in the right sensorimotor cortex, SMA, dorsal and posterior ACC and visual areas. In the effort task, increased activation for increasing prospective gains was also found within the ventral striatum, right hippocampus, ACC and ventral prefrontal regions (OFC, vmPFC Fig. 3B,E). In both effort and risk tasks, there were no decreased activations for increasing prospective gain. Under prospective effort, increased activations for increasing prospective loss were found in right dIPFC and lateral frontal polar cortex, left primary motor cortex, left posterior parietal cortex and medial premotor areas, and there were no decreased activations for increasing prospective loss (Fig. 3C). No activations were found for prospective loss under risk. See supplementary material Table 1., for MNI coordinates of fMRI results.

\subsubsection{Whole-brain subjective value prediction analyses-A parallel set of} parametric analyses (GLM3, GLM4) identified brain regions where activation tracked model predictions of the probability of accepting each gamble. In contrast to the parametric analyses that considered the fixed magnitude of mixed gamble components, these analyses relied upon each participant's choice behavior to generate individual estimates of subjective value for each trial. These analyses revealed shared and distinct contributions of regions for valuation under each prospective cost. The right VS, vmPFC and right sensorimotor cortex tracked value estimates under both prospective costs. Under prospective effort, activity within left dlPFC, right insula and right putamen tracked value estimates (Fig. 4A). Under prospective risk, right IPFC, and bilateral caudate tracked value estimates (Fig. 4B; See supplementary material Table 1 for MNI coordinates of fMRI results, and Figures 1-4 for overlapping maps for each comparison between the different contrasts of interest in the different GLMs). We found significant joint activity within occipital cortex of decreasing activity for increasing prospective effort and risk in the conjunction-null test for overlapping activity of prospective effort and risk. We did not find any significant differences between prospective effort and risk in the paired t-test (see supplementary Figure 5).

\section{Discussion}

We examined the neural basis of effort-based valuation isolated from production demands and outcome resolution. We adapted a prospective mixed gambles choice paradigm to present participants with mixed gambles associated with familiar effort challenges or fixed risk prospects. Participants' choice behavior and confidence ratings separately reflected the imposition of a graded cost upon rewards associated with effort or risk, an observation consistent with many previous effort-based studies (Salamone et al., 2018; Walton et al., 2006). Our neuroimaging analyses focused on the time of choice to reveal activation related to prospective effort or risk cost, and participants' choice behavior. We found a modulation of vmPFC and left sensory cortex at choice by prospective effort magnitude. It has been suggested that vmPFC functions as a global comparator of multimodal valuation (Gläscher et al., 2009; Lebreton et al., 2009; Levy and Glimcher, 2012), and several studies reported 
links between vmPFC activation and effort-based preferences (Basten et al., 2010; Kroemer et al., 2014; Treadway et al., 2012). Activity in primary sensory cortex has been reported to reflect the magnitude of effort demand (Keisker et al., 2009; Schmidt et al., 2012) as well as degree implied physical effort in read descriptions (Moody and Gennari, 2010). Economic theories of decision making models often describe valuation as a cognitive process where options' properties are compared independent of the sensorimotor contingencies (e.g., Padoa-Schioppa, 2011). In contrast, embodied cognition frameworks maintain that motor and sensory inputs are integral components of value representations (Kiefer and Pulvermüller, 2012). Our findings support this interpretation of effort-cost representation as early as the relevant effector sensory cortex (hand area in our task), which in turn putatively relays the information for higher level integration in the vmPFC.

The present findings do not align with related literature that emphasizes the role of the ACC and VS in effort-based valuation processes (Bonnelle et al., 2016; Klein-Flugge et al., 2016; Prévost et al., 2010; Rudebeck et al., 2006; Skvortsova et al., 2014). Our results support recent neurophysiological findings that suggested that the contribution of ACC relates to anticipation or invigoration to effort demands, that are absent in a prospective task (Cowen et al., 2012; Holec et al., 2014). Critical reviews and reports put into question the link of dopamine-related activity within VS to effort and reward expectations (McGinty et al., 2013; Salamone and Correa, 2012), and reframe the role of ACC in valuation as control-based (Shenhav et al., 2013). Likewise, related evidence suggests that ACC activation during foraging decisions reflect inferences of choice difficulty, not value (Shenhav et al., 2014). Bonnelle and colleagues (2016), found that decreased structural and functional connectivity between ACC and SMA were associated with increased behavioral apathy, supporting the role of ACC in action preparation and initiation. A recent study found that while ACC did not correspond to the magnitude of required effort, the dACC together with the anterior insula reflected subjective value prediction error. This suggests that ACC indeed might be involved in expectation rather than effort cost encoding (Arulpragasam et al., 2018). Furthermore, this interpretation is supported by similar neuroimaging studies that did not find significant evidence for ACC modulation by effort cost in prospective effort choice (Bernacer et al., 2016) and voluntary effort-based choices, either physical (Kurniawan et al., 2013) or cognitive (Schouppe et al., 2014). Interestingly, a study that examined the brain correlates of cognitive effort discounting found that only nucleus accumbens activity represented effort demand but that preceding activation in the dorsal anterior cingulate cortex correlated with nucleus accumbens activity (Botvinick et al., 2009). Therefore, we expect that separating cognitive effort valuation from effort production will enable dissociation of ACC and VS contributions to cognitive effort based decisions in a similar way, as in our study.

We found that VS activity corresponded to both prospective gain as well as to the subjective value of the mixed effort and risk gambles. Studies have emphasized a critical role for mesolimbic dopamine as component of the forebrain circuitry regulating effort-related processes (for review see: Salamone et al., 2016, 2007). Findings from human studies provide further support for the role of VS in effort-based decisions. A PET study found that individual differences in left striatal dopamine were correlated with the willingness to expend greater effort for larger rewards, especially when reward probability was low 
(Treadway et al., 2012). Several fMRI studies found an involvement of VS in representing the cost of physical effort (Croxson et al., 2009; Kurniawan et al., 2013) as well as mental effort (Botvinick et al., 2009; Schmidt et al., 2012; Schouppe et al., 2014). Our findings align with evidence for a key role of VS in the representation of integrated cost-benefit valuation..

In addition to identifying regions that tracked effort cost, the goal of our analyses was to relate neural activation at choice to participants' behavior. We used subjective responses to individually predict the probability of accepting each prospective mixed gamble as an estimate of its' subjective value. Notably, the definition of the subjective value of effort remains under debate. Some studies indicate that a sigmoidal shape can best describe effortdiscounting (Klein-Flugge et al., 2016; Massar et al., 2018; although see: Hartmann et al., 2013) and several studies of effort-based decisions have implemented an Accept/Reject approach to evaluate what they refer to as subjective value of effort-cost (Bonnelle et al., 2016, 2015; Chong et al., 2015). Acceptance rate is also commonly used in value-based decision paradigms to evaluate subjective value (Tom et al., 2007). Here, the main aim of the predicted-choice analysis was to account for the integrated valuation of all three components (i.e effort or risk, gain and loss) together in one regressor to represent the subjective value of the mixed gamble offer as a whole. We found that activation of vmPFC and VS as well as visual and motor regions tracked subjective value estimates during choices under both prospective effort and risk. Notably, clusters encompassing insula, putamen and dorsal premotor regions were related to subjective value estimates under prospective effort, whereas prospective risk-based estimates related predominantly to activation of bilateral caudate and right IPFC. These findings accord with evidence that vmPFC and VS comprise a core network for the computation of value during choice while ACC, premotor areas and insular cortex encode arousal or salience (Bartra et al., 2013; Rangel and Clithero, 2013). Similar to other studies of effort-based decisions (Burke et al., 2013; Mathar et al., 2016), our design included an effort task where the participants did not reach the target goal in all of the effort trials. We accounted for this uncertainty component (probability of not making the goal) in our model, yet we acknowledge that future designs should separate between these components.

In the conjunction analysis, we only found significant joint activity within occipital cortex of decreasing activity for increasing prospective effort and risk. In addition, we did not find any significant differences between prospective effort and risk in the paired t-test. We attribute this to the slight differences in location of significant clusters between the separate tasks group results. For example, while we found significant overlapping clusters within sensorimotor cortex for both effort and risk, effort related activity was limited to the postcentral gyrus with a slightly lateral and inferior location. In addition, the whole brain conjunction-null test correction for these analyses might have been overly strict for detecting overlapping activity of the two tasks. Future studies would have to directly address this question in order to clarify to what degree these overlapping brain areas are involved in both types of decision costs.

Several studies have targeted areas within the effort valuation network to treat motivational impairments. Deep transcranial magnetic stimulation of the prefrontal cortex was found to 
improve apathy symptoms in major depression patients (Levkovitz et al., 2011). Another set of studies demonstrated that dopaminergic therapy improved apathy symptoms of Parkinson's disease (Chong et al., 2015) and basal ganglia focal lesions (Adam et al., 2013). Given the great societal cost of maladaptive sensitivity to effort and its role in common impairments to motivated behavior, further understanding of the neural basis of effort-based valuation offers great promise to inform the next generation of behavioral and neurological treatments.

In summary, our results demonstrate the validity of the prospective effort paradigm and refine the association of several brain regions to the process of effort-based valuation that is independent of production. Notably, we provide evidence to support the notion that a common network represents value discounted by effort cost at choice as in other costs such as risk and delay (Kable and Glimcher, 2007; Peters and Buchel, 2009; Tom et al., 2007). While extensive literature supports a crucial role for ACC in effort-based valuation, our results suggest its contribution may be constrained to invigoration or anticipation of upcoming effort production.

\section{Supplementary Material}

Refer to Web version on PubMed Central for supplementary material.

\section{References}

Adam R, Leff A, Sinha N, Turner C, Bays P, Draganski B, Husain M, 2013 Dopamine reverses reward insensitivity in apathy following globus pallidus lesions. Cortex. https://doi.org/10.1016/j.cortex. 2012.04.013

Arulpragasam AR, Cooper JA, Nuutinen MR, Treadway MT, 2018 Corticoinsular circuits encode subjective value expectation and violation for effortful goal-directed behavior. Proc. Natl. Acad. Sci https://doi.org/10.1073/pnas.1800444115

Avants BB, Epstein CL, Grossman M, Gee JC, 2008 Symmetric diffeomorphic image registration with cross-correlation: Evaluating automated labeling of elderly and neurodegenerative brain. Med. Image Anal https://doi.org/10.1016/j.media.2007.06.004

Bartra O, McGuire JT, Kable JW, 2013 The valuation system: A coordinate-based meta-analysis of BOLD fMRI experiments examining neural correlates of subjective value. Neuroimage 76, 412427. https://doi.org/10.1016/j.neuroimage.2013.02.063 [PubMed: 23507394]

Basten U, Biele G, Heekeren HR, Fiebach CJ, 2010 How the brain integrates costs and benefits during decision making. Proc. Natl. Acad. Sci. U. S. A 107, 21767-72. https://doi.org/10.1073/pnas. 0908104107 [PubMed: 21118983]

Bates D, Mächler M, Bolker B, Walker S, 2015 Fitting linear mixed-effects models using lme4. J. Stat. Softw https://doi.org/10.18637/jss.v067.i01

Behzadi Y, Restom K, Liau J, Liu TT, 2007 A component based noise correction method (CompCor) for BOLD and perfusion based fMRI. Neuroimage. https://doi.org/10.1016/j.neuroimage. 2007.04.042

Bernacer J, Martinez-Valbuena I, Martinez M, Pujol N, Luis E, Ramirez-Castillo D, Pastor MA, 2016 Brain correlates of the intrinsic subjective cost of effort in sedentary volunteers, in: Progress in Brain Research. https://doi.org/10.1016/bs.pbr.2016.05.003

Bonnelle V, Manohar S, Behrens T, Husain M, 2016 Individual Differences in Premotor Brain Systems Underlie Behavioral Apathy. Cereb. Cortex https://doi.org/10.1093/cercor/bhv247

Bonnelle V, Veromann KR, Burnett Heyes S, Lo Sterzo E, Manohar S, Husain M, 2015 Characterization of reward and effort mechanisms in apathy. J. Physiol. Paris https://doi.org/ 10.1016/j.jphysparis.2014.04.002 
Botvinick MM, Huffstetler S, McGuire JT, 2009 Effort discounting in human nucleus accumbens. Cogn. Affect. Behav. Neurosci https://doi.org/10.3758/CABN.9.1.16

Brainard DH,1997The Psychophysics Toolbox. Spat. Vis https://doi.org/10.1163/156856897X00357

Burke CJ, Brünger C, Kahnt T, Park SQ, Tobler PN, 2013 Neural Integration of Risk and Effort Costs by the Frontal Pole: Only upon Request. J. Neurosci 33, 1706-1713. https://doi.org/10.1523/ JNEUROSCI.3662-12.2013 [PubMed: 23345243]

Burke CJCJ, Brunger C, Kahnt T, Park SQSQ, Tobler PNPN, Brünger C, Kahnt T, Park SQSQ, Tobler PNPN, 2013 Neural Integration of Risk and Effort Costs by the Frontal Pole: Only upon Request. J. Neurosci 33, 1706-1713. https://doi.org/10.1523/JNEUROSCI.3662-12.2013 [PubMed: 23345243]

Carter RM, Meyer JR, Huettel SA, 2010 Functional neuroimaging of intertemporal choice models: A review. J. Neurosci. Psychol. Econ https://doi.org/10.1037/a0018046

Charnov EL, 1976 Optimal foraging, the marginal value theorem. Theor. Popul. Biol https://doi.org/ 10.1016/0040-5809(76)90040-X

Chong TTJ, Bonnelle V, Husain M, 2016 Quantifying motivation with effort-based decision-making paradigms in health and disease, in: Progress in Brain Research. https://doi.org/10.1016/bs.pbr. 2016.05.002

Chong TTJ, Bonnelle V, Manohar S, Veromann KR, Muhammed K, Tofaris GK, Hu M, Husain M, 2015 Dopamine enhances willingness to exert effort for reward in Parkinson's disease. Cortex. https://doi.org/10.1016/j.cortex.2015.04.003

Chong TTJ, Husain M, 2016 The role of dopamine in the pathophysiology and treatment of apathy, in: Progress in Brain Research. https://doi.org/10.1016/bs.pbr.2016.05.007

Cléry-Melin ML, Schmidt L, Lafargue G, Baup N, Fossati P, Pessiglione M, 2011 Why don't you try harder? an investigation of effort production in major depression. PLoS One. https://doi.org/ 10.1371/journal.pone. 0023178

Clithero JA, Rangel A, 2013 Informatic parcellation of the network involved in the computation of subjective value. Soc. Cogn. Affect. Neurosci 9, 1289-1302. https://doi.org/10.1093/scan/nst106 [PubMed: 23887811]

Cowen SL, Davis GA, Nitz DA, 2012 Anterior cingulate neurons in the rat map anticipated effort and reward to their associated action sequences. J. Neurophysiol https://doi.org/10.1152/jn.01012.2011

Croxson PL, Walton ME, O'Reilly JX, Behrens TEJ, Rushworth MFS, 2009 Effort-based cost-benefit valuation and the human brain. J. Neurosci 29, 4531-4541. https://doi.org/10.1523/JNEUROSCI. 4515-08.2009 [PubMed: 19357278]

Dale AM, Fischl B, Sereno MI, 1999 Cortical surface-based analysis: I. Segmentation and surface reconstruction. Neuroimage. https://doi.org/10.1006/nimg.1998.0395

Day JJ, Jones JL, Wightman RM, Carelli RM, 2010 Phasic nucleus accumbens dopamine release encodes effort- and delay-related costs. Biol. Psychiatry https://doi.org/10.1016/j.biopsych. 2010.03.026

Deichmann R, Gottfried JA, Hutton C, Turner R, 2003 Optimized EPI for fMRI studies of the orbitofrontal cortex. Neuroimage 19, 430-441. https://doi.org/10.1016/S1053-8119(03)00073-9 [PubMed: 12814592]

Esteban O, Markiewicz C, Blair RW, Moodie C, Isik AI, Erramuzpe Aliaga A, Kent J, Goncalves M, DuPre E, Snyder M, Oya H, Ghosh S, Wright J, Durnez J, Poldrack R, Gorgolewski KJ, 2018 FMRIPrep: a robust preprocessing pipeline for functional MRI. bioRxiv.

Fonov V, Evans A, McKinstry R, Almli C, Collins D, 2009 Unbiased nonlinear average ageappropriate brain templates from birth to adulthood. Neuroimage 47, S102 https://doi.org/10.1016/ S1053-8119(09)70884-5

Gläscher J, Hampton AN, O’Doherty JP, 2009 Determining a role for ventromedial prefrontal cortex in encoding action-based value signals during reward-related decision making. Cereb. Cortex https:// doi.org/10.1093/cercor/bhn098

Gold JM, Strauss GP, Waltz JA, Robinson BM, Brown JK, Frank MJ, 2013 Negative symptoms of schizophrenia are associated with abnormal effort-cost computations. Biol. Psychiatry https:// doi.org/10.1016/j.biopsych.2012.12.022 
Gorgolewski K, Burns CD, Madison C, Clark D, Halchenko YO, Waskom ML, Ghosh SS, 2011 Nipype: A Flexible, Lightweight and Extensible Neuroimaging Data Processing Framework in Python. Front. Neuroinform. https://doi.org/10.3389/fninf.2011.00013

Gorgolewski K, Esteban O, Markiewicz CJ, Ziegler E, Ellis DG, Notter MP, Jarecka D, Johnson H, Burns C, Manhães-Savio A, Hamalainen C, Yvernault B, Salo, T M, Waskom M, Clark D, Wong J, Loney F, Modat M, Dewey BE, Madison C, Visconti di Oleggio Castello M, Clark MG, Dayan M, Clark D, Keshavan A, Pinsard B, Gramfort A, Berleant S, 2017 Nipype: a flexible, lightweight and extensible neuroimaging data processing framework in Python.

Gorgolewski KJ, Auer T, Calhoun VD, Craddock RC, Das S, Duff EP, Flandin G, Ghosh SS, Glatard T, Halchenko YO, Handwerker DA, Hanke M, Keator D, Li X, Michael Z, Maumet C, Nichols BN, Nichols TE, Pellman J, Poline JB, Rokem A, Schaefer G, Sochat V, Triplett W, Turner JA, Varoquaux G, Poldrack RA, 2016 The brain imaging data structure, a format for organizing and describing outputs of neuroimaging experiments. Sci. Data https://doi.org/10.1038/sdata.2016.44

Gorgolewski KJ, Varoquaux G, Rivera G, Schwarz Y, Ghosh SS, Maumet C, Sochat VV, Nichols TE, Poldrack RA, Poline J-B, Yarkoni T, Margulies DS, 2015 NeuroVault.org: a web-based repository for collecting and sharing unthresholded statistical maps of the human brain. Front. Neuroinform https://doi.org/10.3389/fninf.2015.00008

Greve DN, Fischl B, 2009 Accurate and robust brain image alignment using boundary-based registration. Neuroimage. https://doi.org/10.1016/j.neuroimage.2009.06.060

Hartmann MN, Hager OM, Tobler PN, Kaiser S, 2013 Parabolic discounting of monetary rewards by physical effort. Behav. Processes https://doi.org/10.1016/j.beproc.2013.09.014

Hillman KL, Bilkey DK, 2012 Neural encoding of competitive effort in the anterior cingulate cortex. Nat. Neurosci https://doi.org/10.1038/nn.3187

Holec V, Pirot HL, Euston DR, 2014 Not all effort is equal: the role of the anterior cingulate cortex in different forms of effort-reward decisions. Front. Behav. Neurosci https://doi.org/10.3389/fnbeh. 2014.00012

Hosokawa T, Kennerley SW, Sloan J, Wallis JD, 2013. Single-Neuron Mechanisms Underlying CostBenefit Analysis in Frontal Cortex. J. Neurosci https://doi.org/10.1523/JNEUROSCI.2221-13.2013

Hull CL, 1943 Principles of Behavior: An Introduction to Behavior Theory. J. Abnorm. Soc. Psychol 39, 377-380. https://doi.org/10.1037/h0051597

Jenkinson M, Bannister P, Brady M, Smith S, 2002 Improved optimization for the robust and accurate linear registration and motion correction of brain images. Neuroimage. https://doi.org/10.1016/ S1053-8119(02)91132-8

Kable JW, Glimcher PW, 2007 The neural correlates of subjective value during intertemporal choice. Nat. Neurosci https://doi.org/10.1038/nn2007

Kao M-H, Mandal A, Lazar N, Stufken J, 2009 Multi-objective optimal experimental designs for event-related fMRI studies. Neuroimage. https://doi.org/10.1016/j.neuroimage.2008.09.025

Keisker B, Hepp-Reymond MC, Blickenstorfer A, Meyer M, Kollias SS, 2009 Differential force scaling of fine-graded power grip force in the sensorimotor network. Hum. Brain Mapp https:// doi.org/10.1002/hbm.20676

Kiefer M, Pulvermüller F, 2012 Conceptual representations in mind and brain: Theoretical developments, current evidence and future directions. Cortex. https://doi.org/10.1016/j.cortex. 2011.04.006

Klein-Flugge MC, Kennerley SW, Friston K, Bestmann S, 2016 Neural signatures of value comparison in human cingulate cortex during decisions requiring an effort-reward trade-off. bioRxiv 36 , 064105 https://doi.org/10.1101/064105

Kroemer NB, Guevara A, Ciocanea Teodorescu I, Wuttig F, Kobiella A, Smolka MN, 2014 Balancing reward and work: Anticipatory brain activation in NAcc and VTA predict effort differentially. Neuroimage. https://doi.org/10.1016/j.neuroimage.2014.07.060

Kurniawan IT, Guitart-Masip M, Dayan P, Dolan RJ, 2013 Effort and Valuation in the Brain: The Effects of Anticipation and Execution. J. Neurosci 33, 6160-6169. https://doi.org/10.1523/ JNEUROSCI.4777-12.2013 [PubMed: 23554497] 
Kurniawan IT, Seymour B, Talmi D, Yoshida W, Chater N, Dolan RJ, 2010 Choosing to make an effort: the role of striatum in signaling physical effort of a chosen action. J. Neurophysiol 104, 313-321. https://doi.org/10.1152/jn.00027.2010 [PubMed: 20463204]

Kuznetsova A, Brockhoff PB, Christensen RHB, 2017 lmerTest package: Tests in linear mixed effects models. J. Stat. Softw https://doi.org/10.18637/jss.v082.i13

Lebreton M, Jorge S, Michel V, Thirion B, Pessiglione M, 2009 An Automatic Valuation System in the Human Brain: Evidence from Functional Neuroimaging. Neuron. https://doi.org/10.1016/j.neuron. 2009.09.040

Lee IM, Shiroma EJ, Lobelo F, Puska P, Blair SN, Katzmarzyk PT, Alkandari JR, Andersen LB, Bauman AE, Brownson RC, Bull FC, Craig CL, Ekelund U, Goenka S, Guthold R, Hallal PC, Haskell WL, Heath GW, Inoue S, Kahlmeier S, Kohl HW, Lambert EV, Leetongin G, Loos RJF, Marcus B, Martin BW, Owen N, Parra DC, Pratt M, Ogilvie D, Reis RS, Sallis JF, Sarmiento OL, Wells JC, 2012 Effect of physical inactivity on major non-communicable diseases worldwide: An analysis of burden of disease and life expectancy. Lancet. https://doi.org/10.1016/ S0140-6736(12)61031-9

Levkovitz Y, Sheer A, Harel EV, Katz LN, Most D, Zangen A, Isserles M, 2011 Differential effects of deep TMS of the prefrontal cortex on apathy and depression. Brain Stimul. https://doi.org/10.1016/ j.brs.2010.12.004

Levy DJ, Glimcher PW, 2012 The root of all value: A neural common currency for choice. Curr. Opin. Neurobiol https://doi.org/10.1016/j.conb.2012.06.001

Massar SAA, Lim J, Sasmita K, Chee MWL, 2018 Sleep deprivation increases the costs of attentional effort: Performance, preference and pupil size. Neuropsychologia. https://doi.org/10.1016/ j.neuropsychologia.2018.03.032

Mathar D, Horstmann A, Pleger B, Villringer A, Neumann J, 2016 Is it worth the effort? Novel insights into obesity- associated alterations in cost-benefit decision-making. Front. Behav. Neurosci https://doi.org/10.3389/fnbeh.2015.00360

McGinty VB, Lardeux S, Taha SA, Kim JJ, Nicola SM, 2013 Invigoration of reward seeking by cue and proximity encoding in the nucleus accumbens. Neuron. https://doi.org/10.1016/j.neuron. 2013.04.010

Meyniel F, Sergent C, Rigoux L, Daunizeau J, Pessiglione M, 2013 Neurocomputational account of how the human brain decides when to have a break. Proc. Natl. Acad. Sci https://doi.org/10.1073/ pnas. 1211925110

Mohr PNC, Biele G, Heekeren HR, 2010 Neural Processing of Risk. J. Neurosci https://doi.org/ 10.1523/JNEUROSCI.0003-10.2010

Moody CL, Gennari SP, 2010 Effects of implied physical effort in sensory-motor and pre-frontal cortex during language comprehension. Neuroimage. https://doi.org/10.1016/j.neuroimage. 2009.07.065

Mumford JA, Nichols TE, 2008 Power calculation for group fMRI studies accounting for arbitrary design and temporal autocorrelation. Neuroimage. https://doi.org/10.1016/j.neuroimage. 2007.07.061

Mumford JA, Poline JB, Poldrack RA, 2015 Orthogonalization of regressors in fMRI models. PLoS One. https://doi.org/10.1371/journal.pone.0126255

Nichols T, Brett M, Andersson J, Wager T, Poline JB, 2005 Valid conjunction inference with the minimum statistic. Neuroimage. https://doi.org/10.1016/j.neuroimage.2004.12.005

Padoa-Schioppa C, 2011 Neurobiology of economic choice: a good-based model. Annu. Rev. Neurosci 34, 333-359. https://doi.org/10.1146/annurev-neuro-061010-113648 [PubMed: 21456961]

Pasquereau B, Turner RS, 2013 Limited Encoding of Effort by Dopamine Neurons in a Cost-Benefit Trade-off Task. J. Neurosci https://doi.org/10.1523/JNEUROSCI.4619-12.2013

Peters J, Buchel C, 2009 Overlapping and Distinct Neural Systems Code for Subjective Value during Intertemporal and Risky Decision Making. J. Neurosci https://doi.org/10.1523/JNEUROSCI. 3489-09.2009

Poldrack RA, Gorgolewski KJ, 2017 OpenfMRI: Open sharing of task fMRI data. Neuroimage. https:// doi.org/10.1016/j.neuroimage.2015.05.073 
Power JD, Mitra A, Laumann TO, Snyder AZ, Schlaggar BL, Petersen SE, 2014 Methods to detect, characterize, and remove motion artifact in resting state fMRI. Neuroimage. https://doi.org/ 10.1016/j.neuroimage.2013.08.048

Prévost C, Pessiglione M, Météreau E, Cléry-Melin M-L, Dreher J-C, 2010 Separate valuation subsystems for delay and effort decision costs. J. Neurosci 30, 14080-14090. https://doi.org/ 10.1523/JNEUROSCI.2752-10.2010 [PubMed: 20962229]

Rangel A, Camerer C, Montague PR, 2008 A framework for studying the neurobiology of value-based decision making. Nat. Rev. Neurosci 9, 545-56. https://doi.org/10.1038/nrn2357 [PubMed: 18545266]

Rangel A, Clithero JA, 2013 The Computation of Stimulus Values in Simple Choice, in: Neuroeconomics: Decision Making and the Brain: Second Edition. https://doi.org/10.1016/ B978-0-12-416008-8.00008-5

Rudebeck PH, Walton ME, Smyth AN, Bannerman DM, Rushworth MFS, 2006 Separate neural pathways process different decision costs. Nat. Neurosci 9, 1161-1168. https://doi.org/10.1038/ nn1756 [PubMed: 16921368]

Rushworth MFS, Behrens TEJ, 2008 Choice, uncertainty and value in prefrontal and cingulate cortex. Nat. Neurosci https://doi.org/10.1038/nn2066

Salamone J, Correa M, Mingote S, Weber S, Farrar A, 2006 Nucleus Accumbens Dopamine and the Forebrain Circuitry Involved in Behavioral Activation and Effort-Related Decision Making: Implications for Understanding Anergia and Psychomotor Slowing in Depression. Curr. Psychiatry Rev https://doi.org/10.2174/157340006776875914

Salamone JD, Correa M, 2012 The Mysterious Motivational Functions of Mesolimbic Dopamine. Neuron 76, 470-485. https://doi.org/10.1016/j.neuron.2012.10.021 [PubMed: 23141060]

Salamone JD, Correa M, Farrar a., Mingote SM, 2007 Effort-related functions of nucleus accumbens dopamine and associated forebrain circuits. Psychopharmacology (Berl). 191, 461-482. https:// doi.org/10.1007/s00213-006-0668-9 [PubMed: 17225164]

Salamone JD, Correa M, Yang J-H, Rotolo R, Presby R, 2018 Dopamine, Effort-Based Choice, and Behavioral Economics: Basic and Translational Research. Front. Behav. Neurosci https://doi.org/ 10.3389/fnbeh.2018.00052

Salamone JD, Yohn SE, López-Cruz L, San Miguel N, Correa M, 2016 Activational and effort-related aspects of motivation: Neural mechanisms and implications for psychopathology. Brain. https:// doi.org/10.1093/brain/aww050

Schmidt L, Lebreton M, Cléry-Melin ML, Daunizeau J, Pessiglione M, 2012 Neural mechanisms underlying motivation of mental versus physical effort. PLoS Biol. https://doi.org/10.1371/ journal.pbio.1001266

Schouppe N, Demanet J, Boehler CN, Ridderinkhof KR, Notebaert W, 2014 The Role of the Striatum in Effort-Based Decision-Making in the Absence of Reward. J. Neurosci https://doi.org/10.1523/ JNEUROSCI.1214-13.2014

Shenhav A, Botvinick MM, Cohen JD, 2013 The expected value of control: An integrative theory of anterior cingulate cortex function. Neuron. https://doi.org/10.1016/j.neuron.2013.07.007

Shenhav A, Straccia MA, Cohen JD, Botvinick MM, 2014 Anterior cingulate engagement in a foraging context reflects choice difficulty, not foraging value. Nat. Neurosci https://doi.org/ 10.1038/nn.3771

Skvortsova V, Palminteri S, Pessiglione M, 2014 Learning To Minimize Efforts versus Maximizing Rewards: Computational Principles and Neural Correlates. J. Neurosci https://doi.org/10.1523/ JNEUROSCI.1350-14.2014

Tom SM, Fox CR, Trepel C, Poldrack R a, 2007 The neural basis of loss aversion in decision-making under risk-Supporting Material. Science 315, 515-8. https://doi.org/10.1126/science.1134239 [PubMed: 17255512]

Treadway MT, Buckholtz JW, Cowan RL, Woodward ND, Li R, Ansari MS, Baldwin RM, Schwartzman AN, Kessler RM, Zald DH, 2012 Dopaminergic Mechanisms of Individual Differences in Human Effort-Based Decision-Making. J. Neurosci https://doi.org/10.1523/ JNEUROSCI.6459-11.2012 
Tustison NJ, Avants BB, Cook PA, Zheng Y, Egan A, Yushkevich PA, Gee JC, 2010 N4ITK: improved N3 \{b\}ias correction. IEEE Trans Med Imaging. https://doi.org/10.1109/TMI.2010.2046908

Wallis JD, Rushworth MFS, 2013 Integrating Benefits and Costs in Decision Making, in: Neuroeconomics: Decision Making and the Brain: Second Edition. https://doi.org/10.1016/ B978-0-12-416008-8.00022-X

Walton ME, Bannerman DM, Alterescu K, Rushworth MFS, 2003 Functional specialization within medial frontal cortex of the anterior cingulate for evaluating effort-trelated decisions. J. Neurosci 23, 6475-6479. https://doi.org/23/16/6475 [pii] [PubMed: 12878688]

Walton ME, Kennerley SW, Bannerman DM, Phillips PEM, Rushworth MFS, 2006 Weighing up the benefits of work: Behavioral and neural analyses of effort-related decision making. Neural Networks 19, 1302-1314. https://doi.org/10.1016/j.neunet.2006.03.005 [PubMed: 16949252]

Zhang Y, Brady M, Smith S, 2001 Segmentation of brain MR images through a hidden Markov random field model and the expectation-maximization algorithm. IEEE Trans. Med. Imaging https://doi.org/10.1109/42.906424 


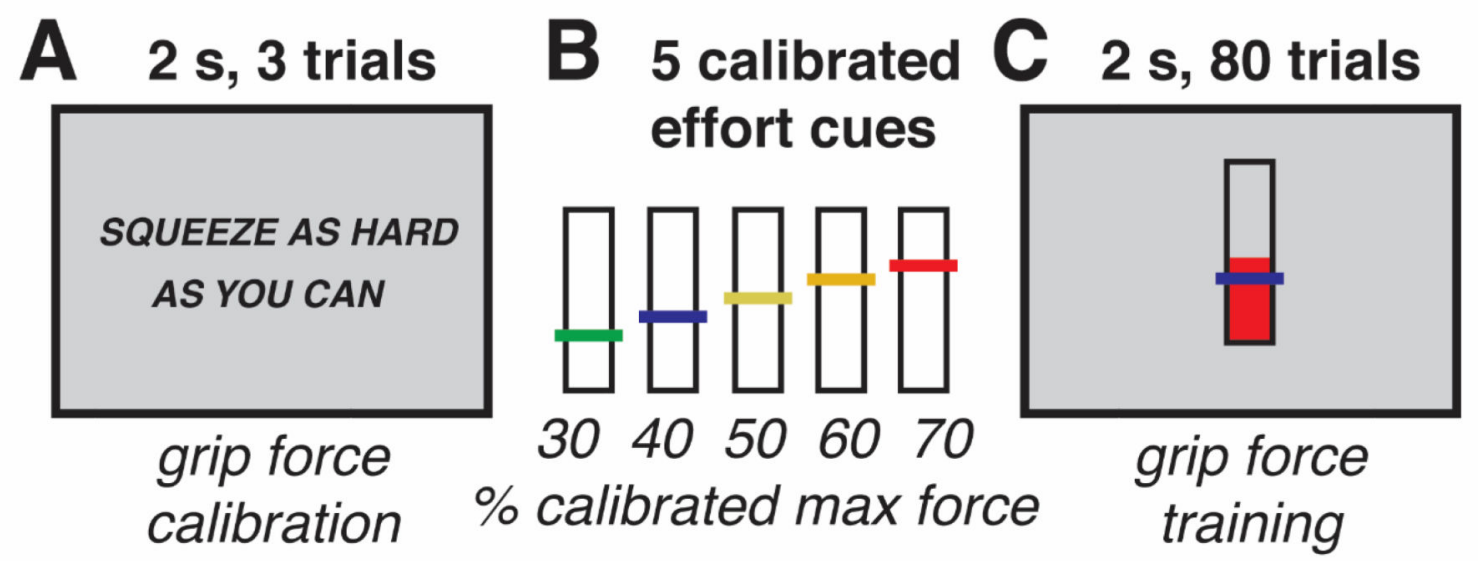

D
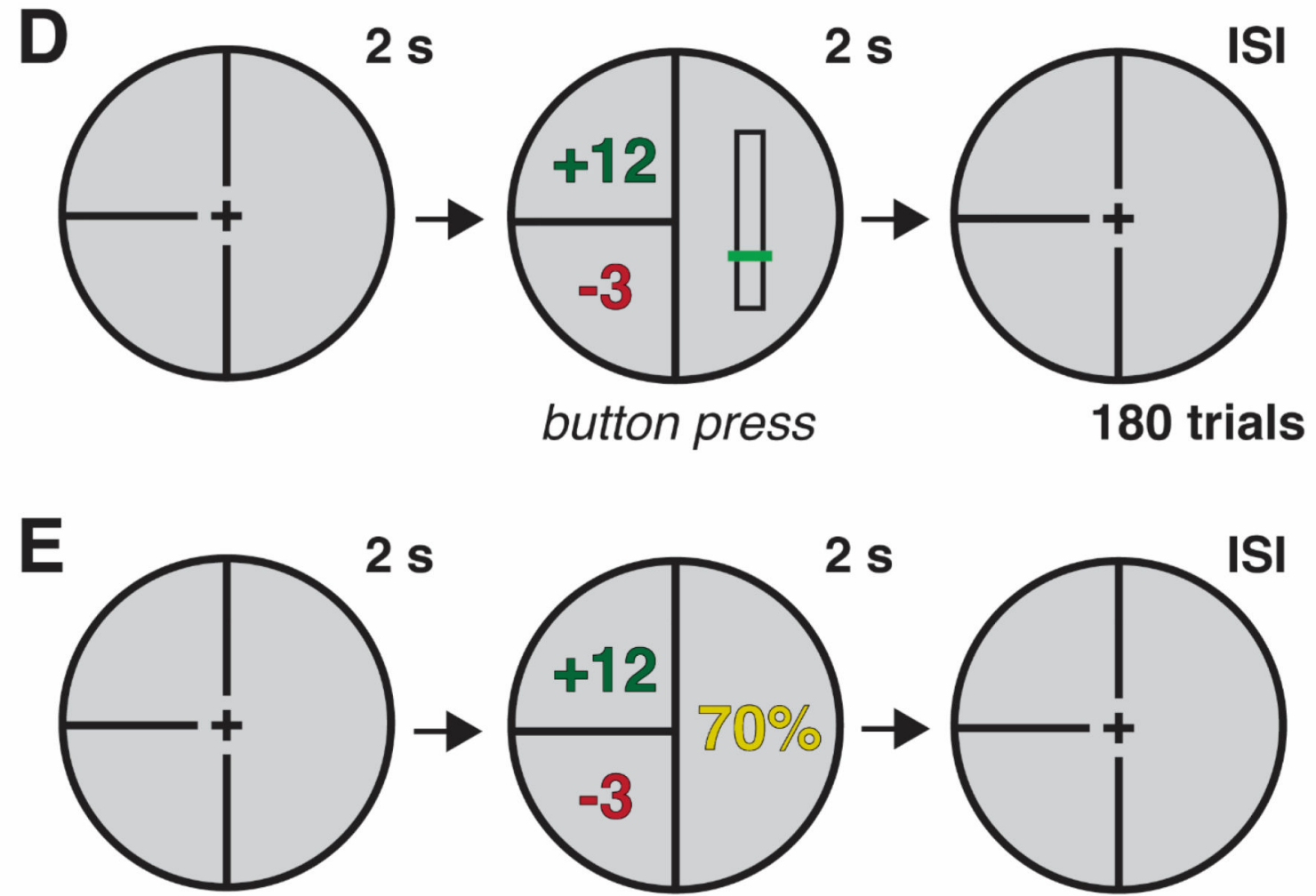

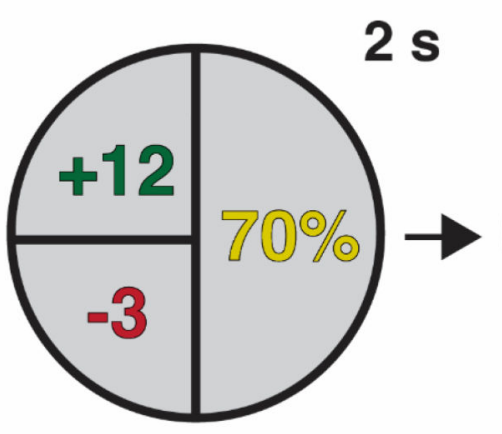

button press

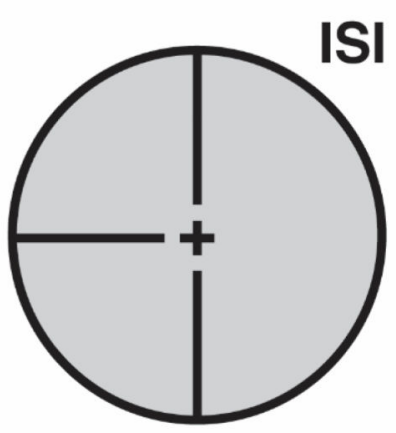

180 trials

Figure 1.

Summary of behavioral task: A) Effort level calibrated for each subject without incentive or feedback. B) Training phase tested performance at 5 calibrated levels of grip force with realtime effort feedback. After training phase, subjects rated subjective attractiveness of prospective effort mixed gambles. C) then prospective risk mixed gambles. D) before resolution of one randomly selected gamble from each session. 


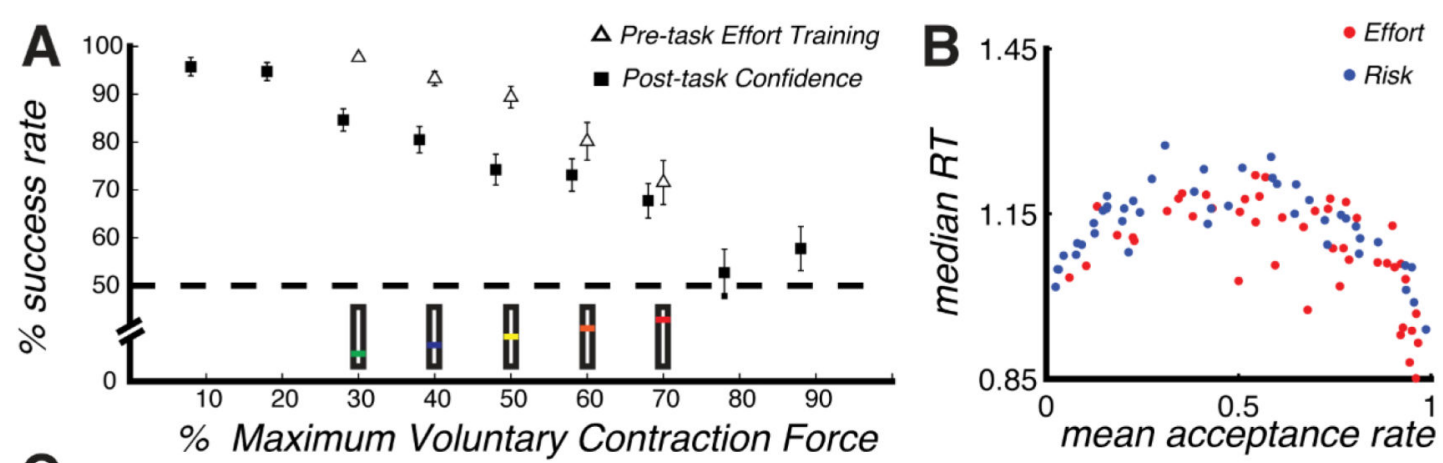

C

\% Maximum Voluntary Contraction Force
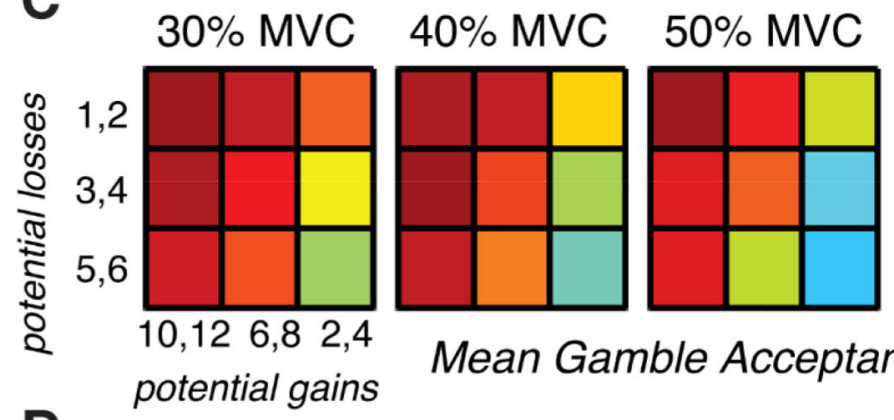

$60 \%$ MVC $\quad 70 \%$ MVC

Mean Gamble Acceptance Rate by Effort Prospect
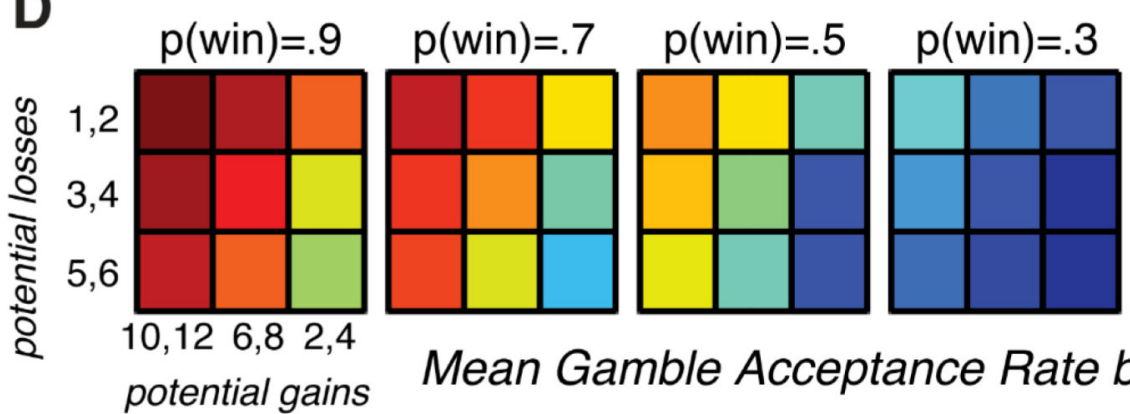

$\mathrm{p}($ win $)=.1$

Figure 2.

Behavioral results: A) Increasing effort levels reduced performance success rate during training and confidence success rate during post-task survey. B) Group normalized median reaction times related to distance from indifference reflected in mean gamble acceptance rates in effort (red) and risk (blue) tasks. C,D) Heat maps depict preferences by level of prospective cost. For illustration, gain and loss were collapsed into 3 levels each. Error bars indicate S.E.M. 


\section{Mixed effort gambles (GLM1) Mixed risk gambles (GLM2)}
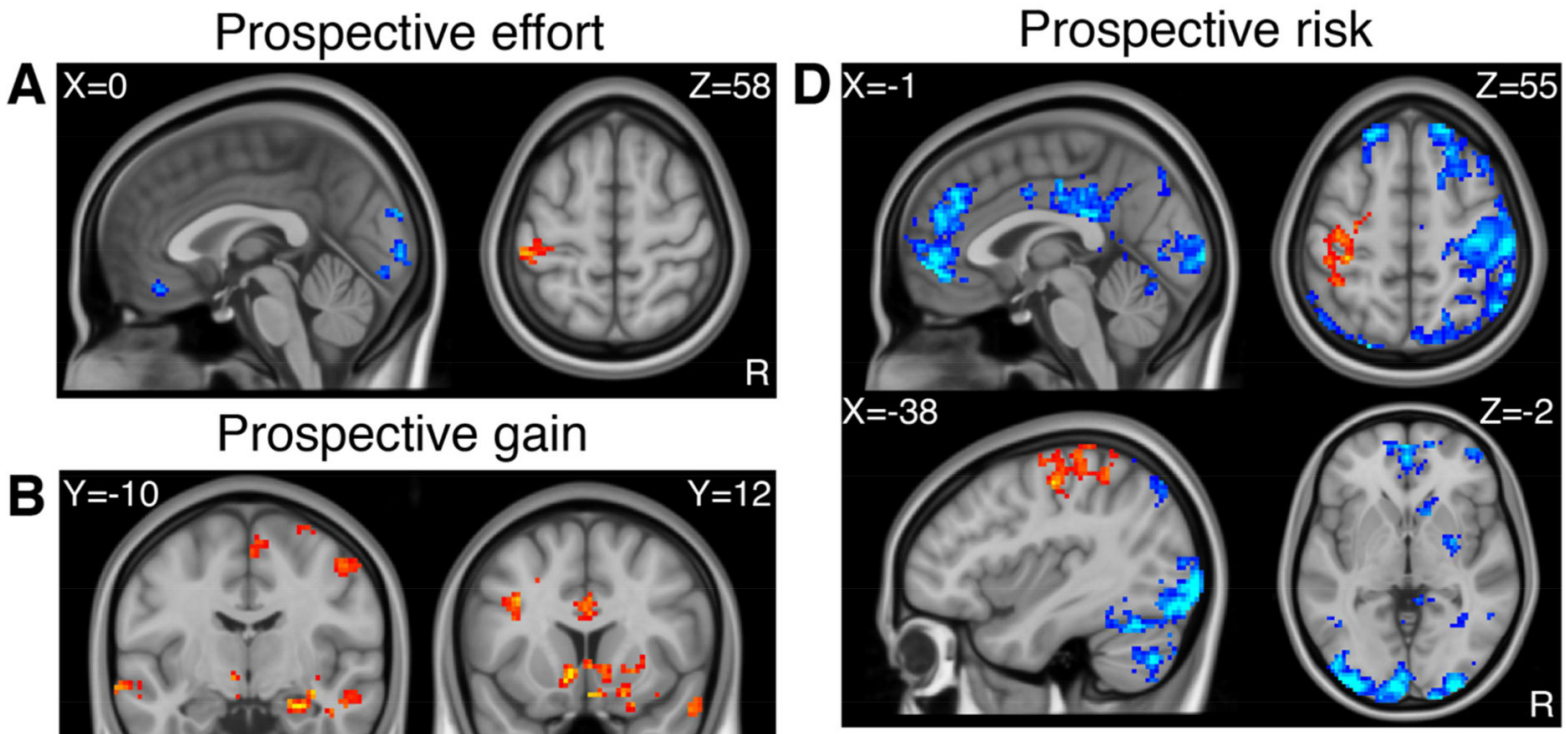

B
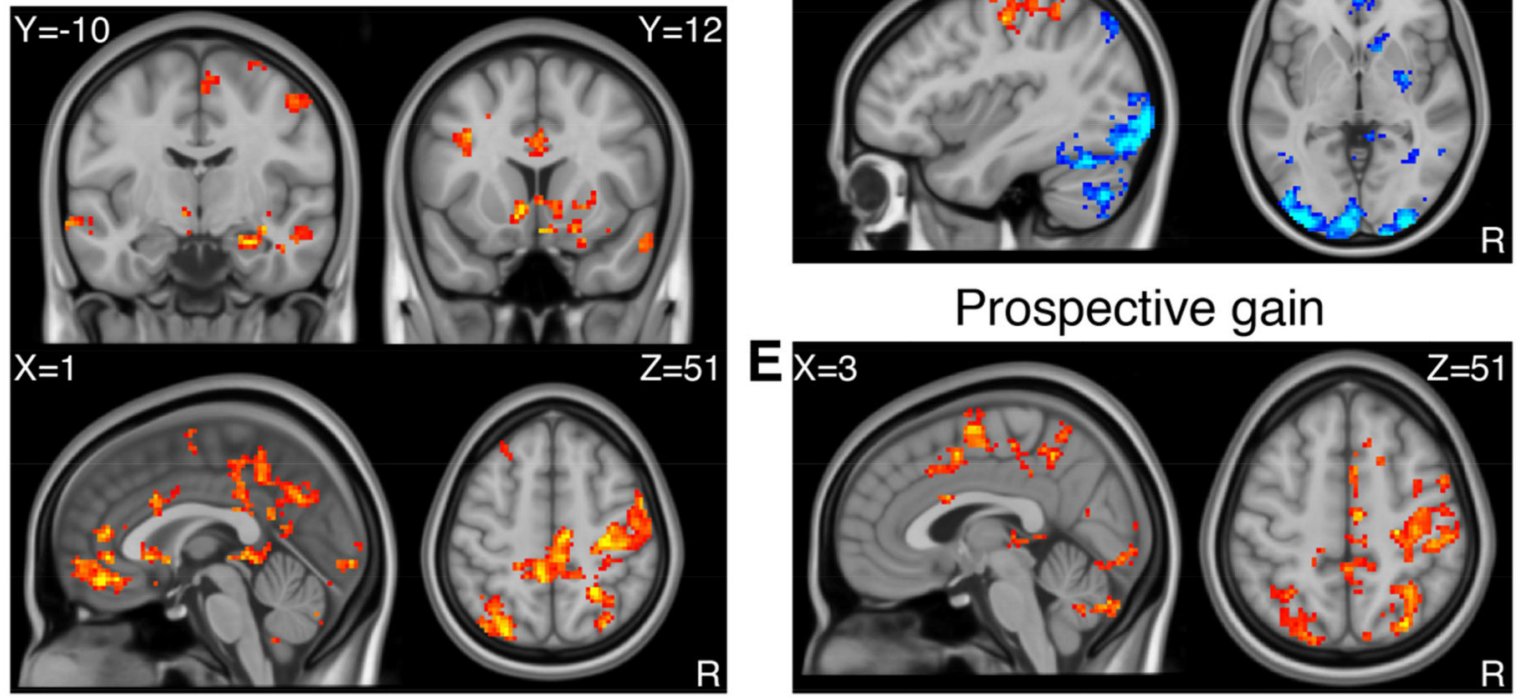

Prospective loss
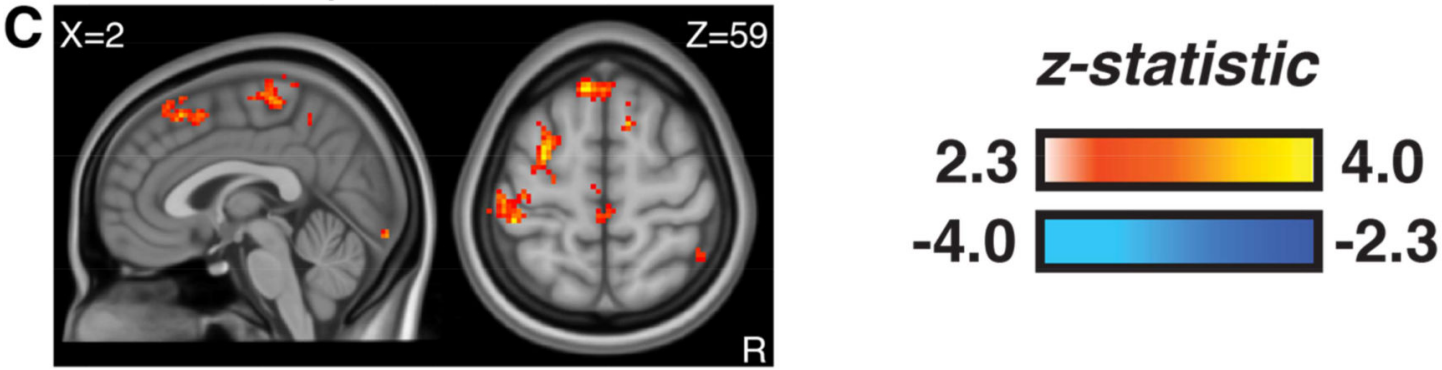

Figure 3.

Parametric activation and deactivation related to magnitude of prospective effort $\mathbf{A}$, potential gain $\mathbf{B}$, and loss $\mathbf{C}$, in effort-based mixed gamble stimuli, and activation related to prospective risk $\mathbf{D}$, and gain $\mathbf{E}$, in risk-based mixed gamble stimuli. Statistical maps corrected for multiple comparisons using Gaussian Random Field Theory at whole-brain level $p<0.05$. 
Subjective value -Prospective effort

A (GLM3)

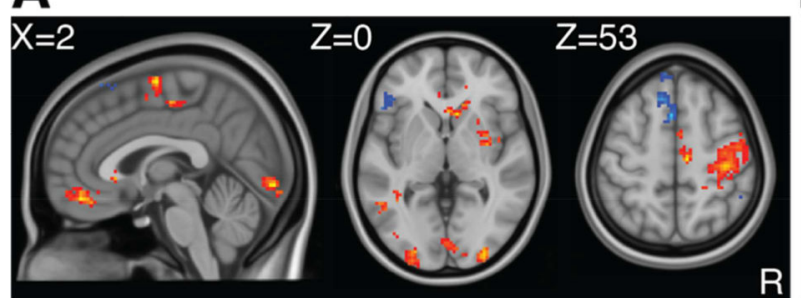

\section{Subjective value -Prospective risk}
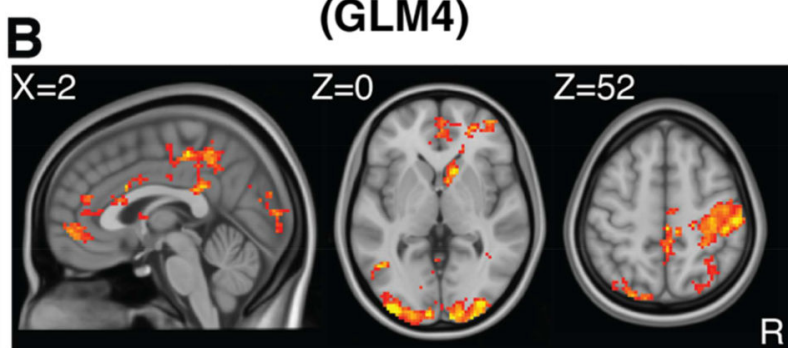

$\mathbf{R}$

$-4.0$

-2.3 z-statistic

2.3

4.0

Figure 4.

Parametric activation and deactivation related to estimates of subjective value from the effort

$\mathbf{A}$, and risk $\mathbf{B}$ tasks. Statistical maps corrected for multiple comparisons at whole-brain gaussian random field theory level $p<0.05$. 
Table 1.

Prospective mixed gambles results

\begin{tabular}{lllll}
\hline & & OR & $95 \%$ CI & p \\
\hline & Effort & 0.32 & {$[0.30,0.35]$} & $<0.001$ \\
Prospective effort mixed gambles & Gain & 3.62 & {$[3.35,3.90]$} & $<0.001$ \\
& Loss & 0.56 & {$[0.52,0.60]$} & $<0.001$ \\
\hline & Risk & 0.11 & {$[0.10,0.12]$} & $<0.001$ \\
Prospective effort mixed gambles & Gain & 3.27 & {$[3.00,3.57]$} & $<0.001$ \\
& Loss & 0.51 & {$[0.48,0.55]$} & $<0.001$ \\
\hline
\end{tabular}

